\title{
Mathematical Model of the Aerial Robotic Camera base on its Geometric Relationship
}

\author{
Mirjana Filipovic \\ Mihajlo Pupin Institute \\ University of Belgrade \\ Ana Djuric \\ Wayne State University \\ Detroit, M \\ U.S.A.
}

This paper introduces a novel mathematical model of the Aerial Robotic Camera (Cable-suspended Parallel Robot-CPR system). The novelty of the $C P R$ model is the geometric relationship between the camera motion in the Cartesian coordinates (external coordinates) and motors angular positions in the joint coordinates (internal coordinates). This relationship is defined by the Jacobian matrix which is used for solving the kinematics and dynamics of the Aerial Robotic Camera. For the computation of the dynamic model, the Lagrange principle of virtual work is used. The Jacobian matrix used in the formulation of the Lagrange principle of virtual work has been adopted according to the construction of the mechanism of the Aerial Robotic Camera. The specific structures of the Aerial Robotic Camera play an important role in defining the kinematic and dynamic models of the CPR system. The general form of the CPR mathematical model is defined and presented. Several numerical examples are used for the CPR model validation.

Keywords: Aerial Robotic Camera, Observation, Workspace, Analysis, Synthesis, Kinematics, Dynamic.

\section{INTRODUCTION}

Different types of Cable-suspended Parallel Robot (CPR system) is developed to some extent and widely analyzed in various research areas as well as for different purposes. For last three decades, researchers have dealt with the mechanisms that carry a camera for space observations or moving objects in space. Similar system groups were analyzed and modelled as evidenced by publications.

In paper [1], the design of a planar three-degree-offreedom parallel manipulator is considered from a kinematic viewpoint. Four different design criteria are established and used to produce designs having optimum characteristics.

The paper [2] presents the first and second order kinematic analysis of a three-degree-of- freedom 3-RPS parallel robot mechanism. The position and orientation parameters of the moving platform of this mechanism are six.

In paper [3] authors present algorithms that enable precise trajectory control of NIMS3D, an under constrained, three-dimensional cabled robot intended for use in actuated sensing. They begin by offering a brief system overview and then describe methods to determine the range of operation of the robot. Next, a discrete-time model of the system is resented.

In paper [4] author presents several prototypes of wire-driven parallel robots, recently designed and which

Received: July 2012, Accepted: January 2014

Correspondence to: Mirjana Filipovic

Mihajlo Pupin Institute, University of Belgrade, Volgina

15, 11000 Belgrade, Serbia,

E-mail: mira@robot.imp.bg.ac.rs

doi:10.5937/fmet1402133F

(C) Faculty of Mechanical Engineering, Belgrade. All rights reserved use two different actuation schemes. Two of them have been completed and submitted to extensive tests. These tests have allowed determining interesting open problems related to kinematics that are presented.

The wrench-closure workspace of parallel cabledriven mechanisms is the set poses of their mobile platform for which the cables can balance any external wrench. The determination of this workspace is an important issue in [5] since the cables can only pull and not push on the mobile platform.

Parallel cable-driven Stewart-Gough platforms consist of an end-effector which is connected to the machine frame by motor driven cables. Since cables can transmit only tension forces, at least $m=n+1$ cables are needed to tense a system having $n$ degrees-offreedom. This results in a kinematical redundancy and leads to a $(m-n)$-dimensional solution space for the cable force distribution presented in [6].

This paper presents the recent results from a newly designed parallel wire robot which is currently under construction. Firstly, an overview of the system architecture is given and technically relevant requirements for the realization are identified. A technique to compute and transfer an estimation of the workspace to CAD tools is presented in [7].

The paper [8] presents an auto-calibration method for over constrained cable-driven parallel robots using internal position sensors located in the motors. A calibration workflow is proposed and implemented including pose selection, measurement, and parameter adjustment.

Wire-driven parallel robot has attracted the interest of researchers since the very beginning of the study of parallel robots [9]. This type of robot has the advantage of having light mobile mass, simple linear actuators 
with possibly relatively large stroke and less risk of interference between the legs. On the other hand their major drawback is that wire actuator can only pull and not push.

A nonlinear dynamic analysis of the suspended cable system is carried out with some sensible results presented in [10] that could be useful to the real engineering of LSRT. Integrated mechanical, electronic, optic and automatic control technologies are employed to make considerable improvement upon the same system.

This work was done for the suspension system in four points. The camera moves quietly and continuously following the observed object. The camera carrier moves in space freely allowing the capture of objects from above. The CPR system has different areas of applications and promising research future. Our goal is to implement this system with maximum precision.

One constructive CPR solution is presented in Section 2. In the same Section, a detailed description of the CPR system and its mathematical model are given. The samples of the system responses are analyzed for different conditions in Section 3. In Section 4, the concluding remarks are presented.

\section{MATHEMATICAL MODEL OF THE CABLE- SUSPENDED PARALLEL ROBOT - CPR SYSTEM}

In this paper, a new original CPR-C system has been developed. Over the pulley system, ropes are run on the winches (reel) 1, 2, 3, powered by motors.

First and second motors are used to wind up the ropes about the coils. During the rotation one side is winding while another side is unwinding.

The third motor is used to wind up the two ropes about the coil only in one direction. Those motion produce winding or unwinding of both ropes at the same time. This can be seen in Fig. 1. Ropes coil on winches has radius $R$.

Synchronous motion of the motors, produce motion of the camera carrier in the $x, y, z$ Cartesian space. The desired motion trajectory of the camera is defined in $\mathrm{x}$, $\mathrm{y}, \mathrm{z}$ Cartesian coordinates, and it is generated by motion of three motors $\theta_{1}, \theta_{2}, \theta_{3}$. The kinematic model of the CPR-C system has been developed as essential part for solving the CPR-C system dynamics. See Fig. 1.

The relation between the camera motion in the Cartesian space $x, y, z$ and angular positions of each motor $\theta_{1}, \theta_{2}, \theta_{3}$ is solved by the Jacobian matrix $J_{c}$, which connects velocities of external coordinates changes $\dot{p}=\left[\begin{array}{lll}\dot{x} & \dot{y} & \dot{z}\end{array}\right]^{T}$ with velocities of internal coordinates changes $\dot{\varphi}=\left[\begin{array}{lll}\dot{\theta}_{1} & \dot{\theta}_{2} & \dot{\theta}_{3}\end{array}\right]^{T}$. For generation of any trajectory in $x, y, z$ space, it is necessary to provide very precise and mutually coordinated motion of all three motors $\theta_{1}, \theta_{2}, \theta_{3}$.

The $3 \mathrm{D}$ recorded space has a parallelepiped shape of length $d$, width $s$, and height $v$. In this 3D space it can be seen that the camera is connected with the ropes. See Fig. 1b). The connecting dimensions are $\delta_{x 1}, \delta_{x 2}, \delta_{y 1}, \delta_{y 2}$. These dimensions are very small in comparison with the complete $3 \mathrm{D}$ recorded space. From this observation it is clear that $\delta_{x l} \approx 0, \delta_{x 2} \approx 0, \delta_{y l} \approx 0, \delta_{y 2} \approx 0$. It is also assumed that the pivot point $\mathrm{A}$ at height $z$ is equal to the heights of all three connecting points.

This fact allows us to choose a point $A$ as a hanging position of the camera carrier for all three ropes, see Fig. 1. This camera carrier system can be easily constructed. This assumption simplifies the definition of geometric relations between camera carrier motion in Cartesian coordinates and coordinated motions of all motors.

The geometrical relationship between the lengths $k$, $h, m, n$, and Cartesian coordinates $x, y, z$, is defined by the following equations:

$$
\begin{gathered}
k=\sqrt{x^{2}+y^{2}+z^{2}} \\
h=\sqrt{(d-x)^{2}+y^{2}+z^{2}} \\
m=\sqrt{(d-x)^{2}+(s-y)^{2}+z^{2}} \\
n=\sqrt{x^{2}+(s-y)^{2}+z^{2}}
\end{gathered}
$$

For every sampling time the relations are defined:

$$
\begin{gathered}
\frac{\Delta \theta_{1}}{\Delta t} \cdot R=\frac{\Delta m}{\Delta t}+\frac{\Delta h}{\Delta t} \\
\frac{\Delta \theta_{2}}{\Delta t} \cdot R=\frac{\Delta k}{\Delta t}+\frac{\Delta h}{\Delta t} \\
\frac{\Delta \theta_{3}}{\Delta t} \cdot R=\frac{\Delta n}{\Delta t}+\frac{\Delta k}{\Delta t}+\frac{\Delta \theta_{1}}{\Delta t} \cdot R
\end{gathered}
$$

The equation (8) is obtained by substituting (5) into the (7):

$$
\frac{\Delta \theta_{3}}{\Delta t} \cdot R=+\frac{\Delta k}{\Delta t}+\frac{\Delta h}{\Delta t}+\frac{\Delta m}{\Delta t}+\frac{\Delta n}{\Delta t}
$$

If the sampling time $\Delta t$ is small enough it follows that:

$$
\begin{gathered}
\dot{\theta}_{1} \cdot R=\dot{m}+\dot{h} \\
\dot{\theta}_{2} \cdot R=\dot{k}+\dot{h} \\
\dot{\theta}_{3} \cdot R=+\dot{k}+\dot{h}+\dot{m}+\dot{n}
\end{gathered}
$$

By differentiating (1)-(4) and substituting them into the (9)-(11), the relationship between velocities of external coordinates changes $\dot{p}=\left[\begin{array}{lll}\dot{x} & \dot{y} & \dot{z}\end{array}\right]^{T}$ and velocities of internal coordinates changes $\dot{\phi}=\left[\begin{array}{lll}\dot{\theta}_{1} & \dot{\theta}_{2} & \dot{\theta}_{3}\end{array}\right]^{T}$ has been obtained:

$$
\begin{gathered}
\dot{\phi}=J_{c} \cdot \dot{p} \\
J_{c}=\left[\begin{array}{lll}
J_{c 11} & J_{c 12} & J_{c 13} \\
J_{c 21} & J_{c 22} & J_{c 23} \\
J_{c 31} & J_{c 32} & J_{c 33}
\end{array}\right]
\end{gathered}
$$




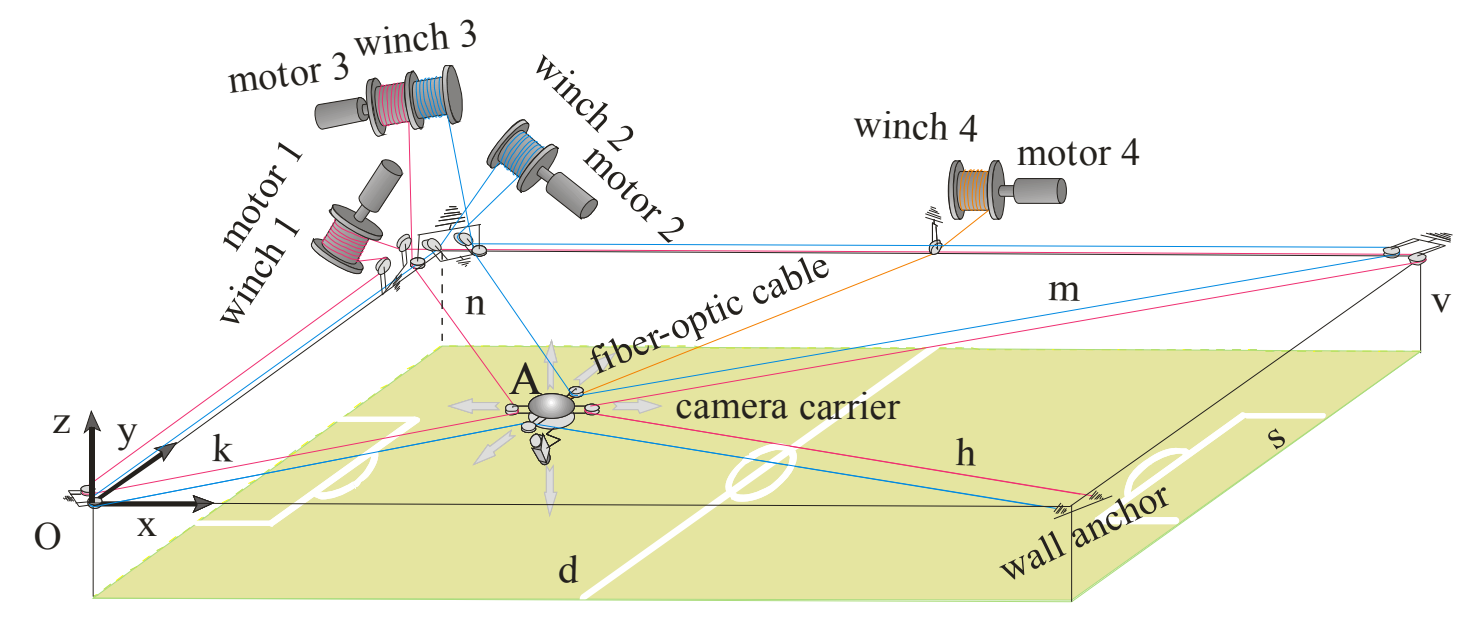

a)

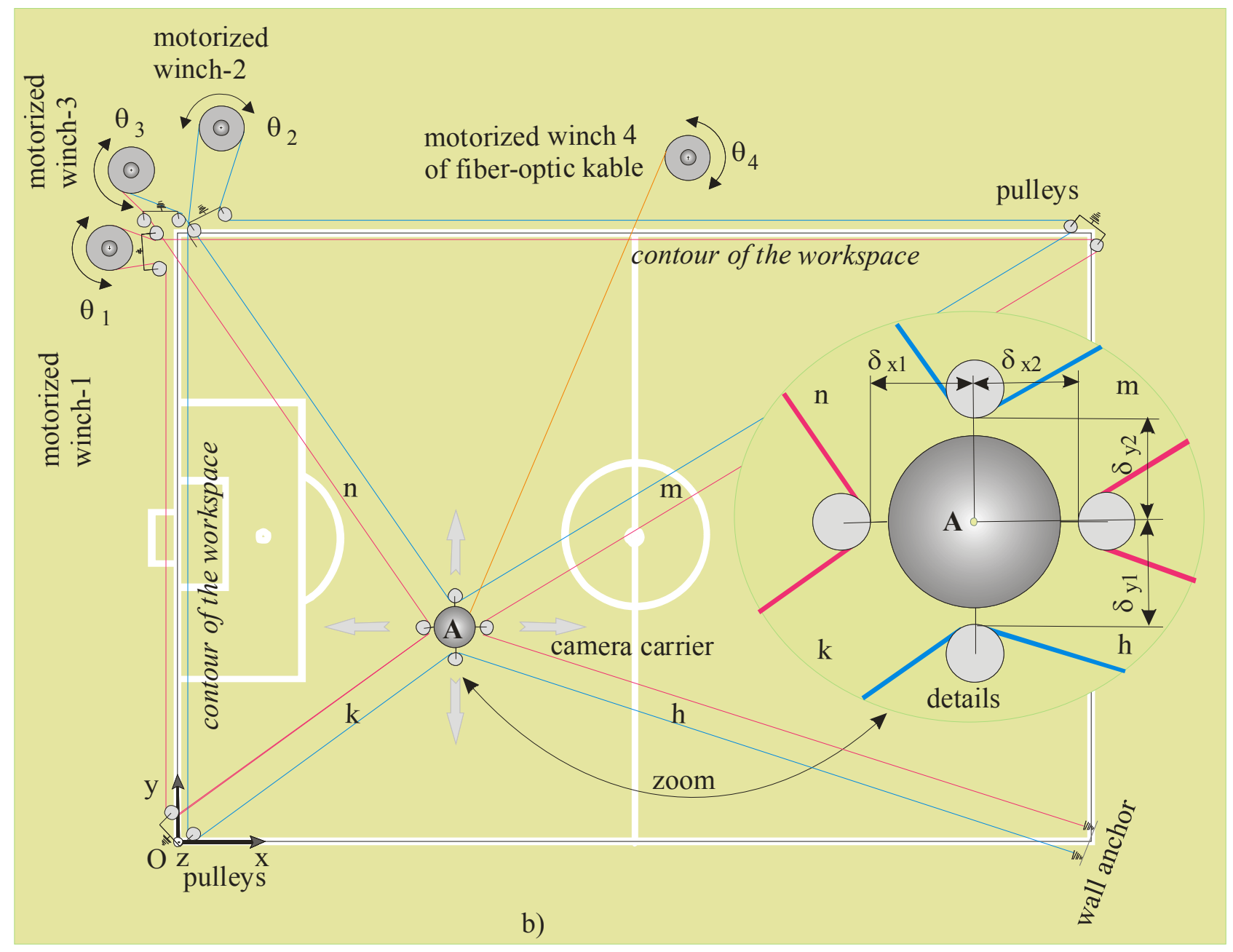

Figure 1. CPR-C SYSTEM, a) in 3D, b) top view

It is evident that Jacobian matrix $J_{c}$ in (13) is not diagonal but full matrix. The elements of this matrix beyond diagonal show the strong coupling between the external and internal coordinates.

The camera carrier together with the camera represents a small system in a comparison to the complete work area. In that case the small system has negligible moments of inertia about each axis of the local coordinate system at the point $A$.
For the camera dynamics modeling, the camera is presented as a material particle with 3 DOF in the $x, y$, $z$ Cartesian coordinates system.

The kinetic energy $E_{k}$ and potential $E_{p}$ energy of the camera carrier motion with mass $m$ are given in the following equations:

$$
E_{k}=1 / 2 \cdot m \cdot \dot{x}^{2}+1 / 2 \cdot m \cdot \dot{y}^{2}+1 / 2 \cdot m \cdot \dot{z}^{2}
$$




$$
E_{p}=m \cdot g \cdot z
$$

First the analysis was done where the ropes are rigid. In that case a system mathematical model has the following form:

$$
u=G_{v} \cdot \ddot{\phi}+L_{v} \cdot \dot{\phi}+S_{v} \cdot M_{c}
$$

Vector equation (16) is given by applying Lagrange's equation of the second order on generalized coordinates $\theta_{1}, \theta_{2}, \theta_{3}$, where:

$$
\begin{aligned}
& u=\left[\begin{array}{lll}
u_{1} & u_{2} & u_{3}
\end{array}\right]^{T}, G_{v(3 \times 3)}=\operatorname{diag} G_{v i}, \\
& L_{v(3 \times 3)}=\operatorname{diag} L_{v i}, S_{v(3 \times 3)}=\operatorname{diag} S_{v i} .
\end{aligned}
$$

The main motor load moment $M_{c}$ is defined with the vector's equation (17).

$$
M_{c}=F_{c} \cdot R
$$

The main force $F_{c}=\left[\begin{array}{lll}F_{1} & F_{2} & F_{3}\end{array}\right]^{T}$ is acting on the shaft of each motor, and its value depends of the external force $F$.

$$
F_{c}=\frac{\left(\left(J_{{ }_{\Delta}}\right)^{T}\right)^{-1}}{R} \cdot F
$$

The external force $F$ represents the sum of the inertial force $F_{p}$ which is acting on the camera carrier described in (20), and the perturbation force $P_{p}$ which is disturbing the camera motion.

$$
\begin{gathered}
F=\left(F_{p}+P_{p}\right) \\
F_{p}=m \cdot\left(\ddot{p}+a_{c c}\right)
\end{gathered}
$$

Vector $a_{c c}=\left[\begin{array}{lll}0 & 0 & -g\end{array}\right]^{T} \quad$ represents the gravitational acceleration.

The force mapping vector $C_{c}$ depends only on the geometry of the observed mechanism and selected motion trajectory of the camera carrier during the robotic task. The determination of the force mapping vector $C_{c}$ is complex and it highly depends on the imagination of researchers, which can cause the errors. In order to define (21), the Lagrange's principle of virtual work has been used to find the relation between the main force $F_{c}$ and the external force $F$.

$$
\begin{aligned}
& C_{c}=\frac{\left(\left(J_{\Delta_{c}}\right)^{T}\right)^{-1}}{R} \\
& J_{\diamond_{c}}=f\left(\diamond, J_{c}\right)
\end{aligned}
$$

Since the CPR-C system has two parallel ropes, suspending cameras in all four directions $k, h, m, n$, then (22) has the following form:

$$
J_{\diamond c}=\diamond \cdot J_{c}
$$

The presence of factors $\diamond$ is a consequence of structural systems with Fig. 1.

$\diamond=1 / 2$ is a factor which multiplies only the direction of two parallel ropes. In this direction, a force in each rope is a half of the force impact $F$ that is acting on the camera carrier. Observed CPR-C model has two ropes from a camera carrier to all four-point suspension (line $k, h, m, n$ ).

The relation between the main forces $F_{c}$ and total force $F$ acting on a camera carrier in Cartesian space is given by (18). This is a geometrical relationship, which is uniquely defined.

In order to obtain the relationship between internal and external forces, the virtual work principle can be applied. Equation (18) is particularly important because it participates in the configuration of the CPR-C dynamic model.

Vector main force acting on the shaft of each motor is $F_{c}=\left[\begin{array}{lll}F_{1} & F_{2} & F_{3}\end{array}\right]^{T}$.

Substituting (17)-(23) into the (16) produce a dynamic model of CPR-C system which is expressed in (24):

$$
u=G_{v} \cdot \ddot{\phi}+L_{v} \cdot \dot{\phi}+S_{v} \cdot R \cdot C_{c} \cdot F
$$

The force mapping vector $C_{c}$ describes a strong coupling between the presented motors.

Control law is selected by the local feedback loop for position and velocity of the motor shaft in the following form:

$$
u_{i}=K_{l p i} \cdot\left(\theta_{i}^{o}-\theta_{i}\right)+K_{l v i} \cdot\left(\dot{\theta}_{i}^{o}-\dot{\theta}_{i}\right)
$$

\section{SIMULATION EXAMPLE}

In order to make results comparable, they are made for the same desired trajectory and the same for all other system parameters, as defined in the Nomenclature.

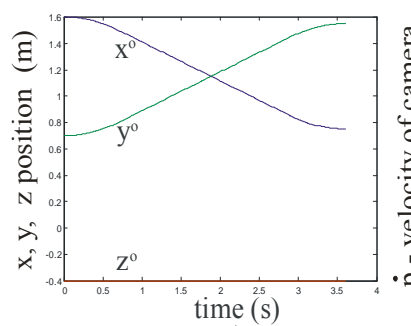

a)

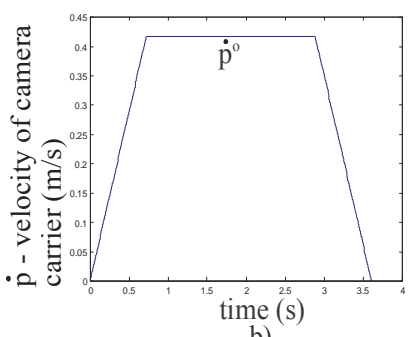

b)
Figure 2. The reference trajectory motion of a) position $x^{0}$, $\left.y^{0}, z^{0}, \mathbf{b}\right)$ velocity of camera carrier $\dot{p}_{\max }^{o}=0.417[\mathrm{~m} / \mathrm{s}]$

Camera carrier has the starting point $p_{\text {start }}^{o}=\left[\begin{array}{lll}1.6 & 0.7 & -0.4\end{array}\right][m]$, and the end point $p_{\text {end }}^{o}=\left[\begin{array}{lll}0.75 & 1.55 & -0.4\end{array}\right][m]$. See Fig. 2a).

The camera moves in $x$ and $y$ directions, whiles the coordinate $z$ is constant. Camera motion velocity has a trapezoid form and $\dot{p}_{\max }^{o}=0.417[\mathrm{~m} / \mathrm{s}]$, as shown in Fig. 2b). 
The motors are of Heinzman SL100F type and gears are HFUC14-50-2A-GR+belt.

Some important characteristics of CPR-C system are: gravitational acceleration $g=9.81\left(\mathrm{~m} / \mathrm{s}^{2}\right)$, sample time $d t=0.0001(\mathrm{~s})$, winch radius $R_{i}=0.15(\mathrm{~m})$, rotor circuit resistance $R_{r i}=0.917(\Omega)$, back electromotive force constant $C_{E i}=3.3942(\mathrm{~V} /(\mathrm{rad} / \mathrm{s}))$, constant of the moment proportionality $C_{M i}=2.5194(\mathrm{Nm} / \mathrm{A})$, coefficient of viscous friction $B_{C i}=0.0670(\mathrm{Nm} /(\mathrm{rad} / \mathrm{s}))$, moment of inertia for the rotor and the gear box $J_{r i}=1.5859\left(\mathrm{kgm}^{2}\right)$, motor inertia characteristic $G_{v i}=\frac{J_{r i} \cdot R_{r i}}{C_{M i}}=0.1787$, motor damping characteristic $L_{v i}=\frac{R_{r i} \cdot B_{C i}}{C_{M i}}+C_{E i}=3.4186$, motor geometric characteristic $S_{v i}=\frac{R_{r i}}{C_{M i}}=0.364$, mass of the camera carrier $m=1(\mathrm{~kg})$, length of the recorded field $d=3.2(\mathrm{~m})$, width of the recorded field $s=2.2(\mathrm{~m})$, height of the recorded field $v=2.0(\mathrm{~m})$, initial deviation of the motor angular position $\delta \theta_{i \Xi}=0(\mathrm{rad}), \delta \dot{\theta}_{i \Xi}=0(\mathrm{rad} / \mathrm{s}), \quad$ positional $K_{l p i}=4200$, velocity $K_{l v i}=130$ amplification for motion control and factor that characterizes two parallel guided ropes $\diamond=0.5$.

Example 1: The example CPR-C system from Fig. 1 is analyzed.

The system mathematical model at the reference frame is defined by (12)-(24). All three motors $\theta_{1}, \theta_{2}$ and $\theta_{3}$ must participate in the solution of this task.

This is shown in Fig. 3b), and it is a proof that all these motions are mutually coupled.

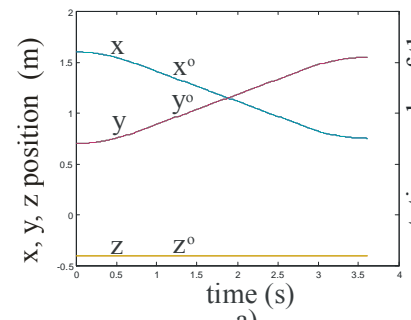

a)

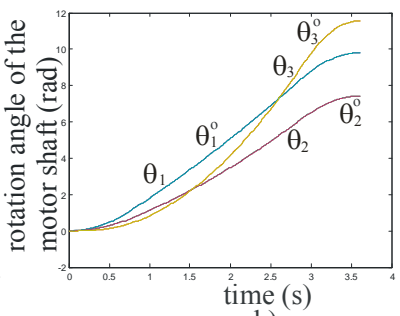

b)
Figure 3. a) Reference frame and real coordinate $x, y, z$ of camera carrier, b) reference and real coordinate $\theta_{1}, \theta_{2}$, $\theta_{3}$ of motor shaft, (Example 1)

There is a good tracking of a desired trajectory at the level of motor motions (in the order of about $10^{-3}[\mathrm{rad}]$, see Fig. 4b) and Fig. 3b)) and at the level of motion of the camera carrier (on the order of about $10^{-4}[\mathrm{~m}]$, see Fig. 4a) and Fig. 3a)).

The level of control signals is given in Fig. 5b) and does not exceed the limits of $\pm 24[\mathrm{~V}]$. In Fig. 5a) there are three main forces that are not exceeding $16[N]$.
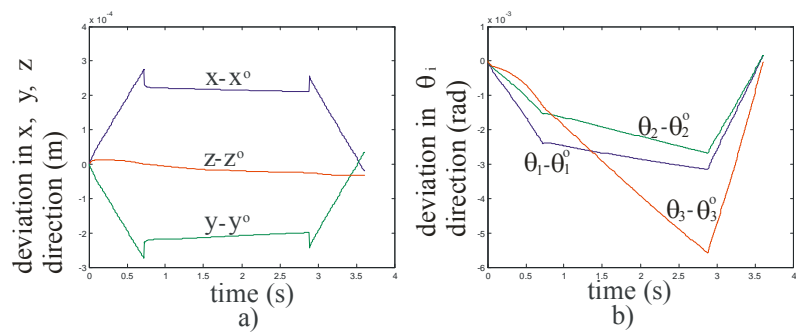

Figure 4. a) Deviation real from the reference frame values of a motion trajectory of camera carrier, b) deviation real from the reference frame values of a motion trajectory of motor shaft, (for CPR-C, Example 1)

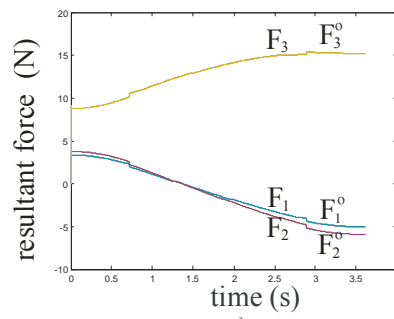

a)

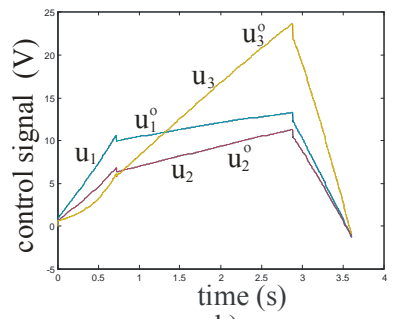

b)
Figure 5. a) Reference frame and real main forces $F_{i}$, b) reference frame and real control signal $u_{i}$, (Example 1)

Example 2: The example from Fig. 1 is analyzed. All system and control parameters are the same as in the Example 1. This example is done with one illogical assumption, which is the case when the system user assumes that the system at the reference level is uncoupled. In that case the Jacobian matrix has the diagonal form:

$$
\begin{gathered}
\dot{\varphi}=J_{c \oplus} \cdot \dot{p} \\
J_{c \oplus}=\left[\begin{array}{ccc}
J_{c 11} & 0 & 0 \\
0 & J_{c 22} & 0 \\
0 & 0 & J_{c 33}
\end{array}\right] \\
u=G_{v} \cdot \ddot{\phi}+L_{v} \cdot \dot{\phi}+S_{v} \cdot M_{c \oplus} \\
M_{c \oplus}=F_{c \oplus} \cdot R
\end{gathered}
$$

The main force is defined as:

$$
\begin{aligned}
& F_{c \oplus}=\frac{\left(\left(J_{\Delta_{c} \oplus}\right)^{T}\right)^{-1}}{R} \cdot F \\
& C_{c \oplus}=\frac{\left(\left(J_{{ }_{\Delta c} \oplus}\right)^{T}\right)^{-1}}{R} \\
& J_{{ } \oplus}=\diamond \cdot J_{c \oplus} \\
& u=G_{v} \cdot \ddot{\varphi}+L_{v} \cdot \dot{\varphi}+S_{v} \cdot R \cdot C_{c \oplus} \cdot F
\end{aligned}
$$

Directly follows that the matrix $C_{c \oplus}$ is diagonal like matrix $J_{c \oplus}$.

Unlike the previous example, the mathematical model of the system at the reference level in this example is defined by (26), (27), (14), (15), (28)-(31), (19), (20), (32), (33). At the real level the system is 
coupled and its kinematic and dynamic model is defined by (12)-(24).

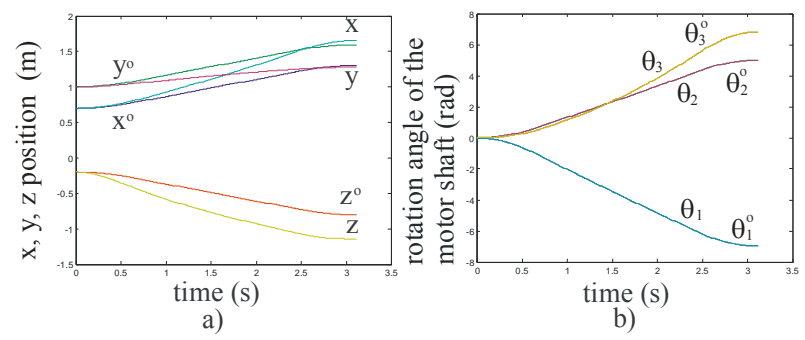

Figure 6. a) Reference frame and real coordinate $x, y, z$ of camera carrier, b) reference and real coordinate $\theta_{1}, \theta_{2}$, $\theta_{3}$ of motor shaft, (Example 2)

Fig. 6a) shows the results of the camera carrier motion in all three directions of the Cartesian coordinate frame $x, y, z$ and the reference frame $x^{0}, y^{0}, z^{0}$.

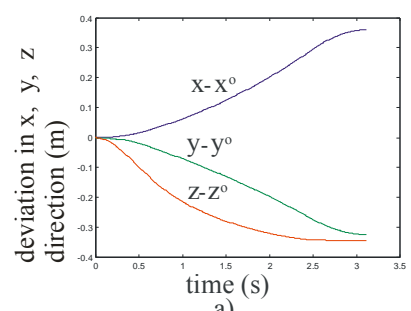

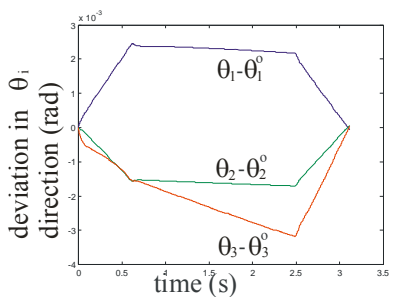

b)
Figure 7. a) Deviation real from the reference frame values of a motion trajectory of camera carrier, $b$ ) deviation real from the reference frame values of a motion trajectory of motor shaft, (Example 2)

Trajectory of motor angular positions at the real frame $\theta_{1}, \theta_{2}, \theta_{3}$ and reference $\theta_{1}^{o}, \theta_{2}^{o}, \theta_{3}^{o}$ frame is given in Fig. 6b).

Since the positional control law is applied (with local feedback on the position and velocity) for each motor angular position, defined in (25), the control of motor motion is ideal. See Fig. 7b). However, the coupling characteristics are not taken into the consideration at the reference frame, and because of that there is no good enough tracking of a real trajectory comparing to the reference signal in the Cartesian space, see Fig. 7a).

The unknown coupling characteristics significantly affect the accuracy of the trajectory tracking, which value reaches $\left(x-x^{o}\right)_{\max }=0.36[m]$ in this example.

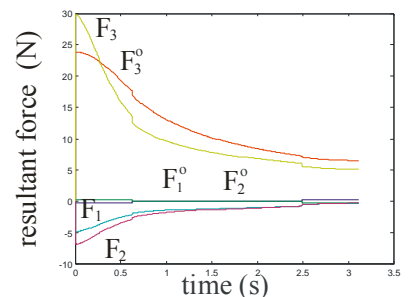

a)

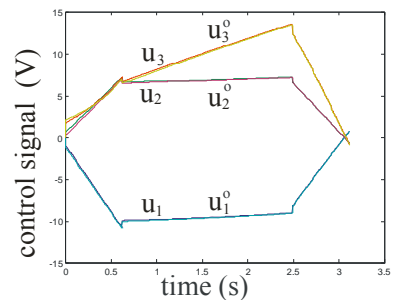

b)
Figure 8. a) Reference frame and real main forces $F_{i}$, b) reference frame and real control signal $u_{i}$, (Example 2)

The value of control signals is given in Fig. 8b) and it does not exceed the limits of $\pm 24[\mathrm{~V}]$. In Fig. 8a) there are three main forces that are not exceeding $30[N]$.
Example 3: The importance of this example is that the camera carrier mass of $m=3[\mathrm{~kg}]$ is three times higher comparing to the one in Example 1. All other system parameters are the same. The system mathematical model at the reference frame is defined by (12)-(24).

It can be seen in Fig. 9a) (Fig. 10a)) and Fig. 9b) (Fig. 10b)) that the desired trajectory at the camera motion frame and at the motor motion frame is worse than in Example 1. This is because the selected motors are not strong enough to carry larger mass of the camera carrier.

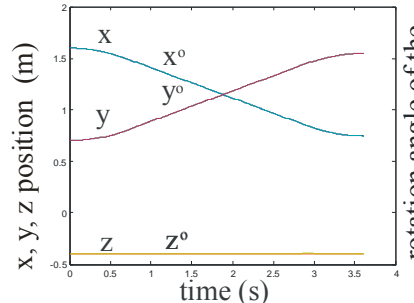

a)

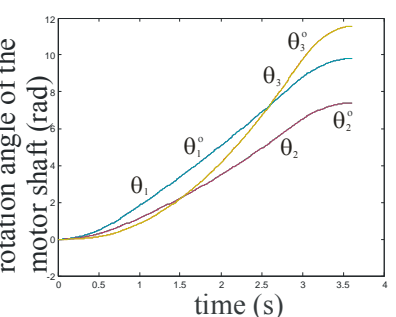

b)
Figure 9. a) Reference frame and real coordinate $x, y, z$ of camera carrier, b) reference and real coordinate $\theta_{1}, \theta_{2}$, $\theta_{3}$ of motor shaft, (Example 3)

The third motor achieves the saturation point at $t=2.7$ [s] referred to the real and reference frames. At the reference frame the signal goes out of saturation at 2.9 [s], while at the real frame it goes out of saturation at $t=3$ [s]. See Fig. 11b). The first and second motors do not enter saturation at all.

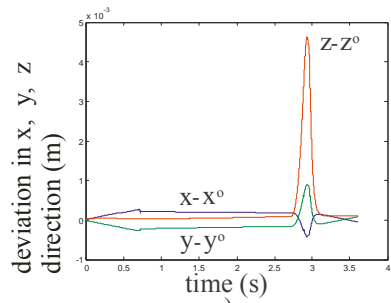

a)

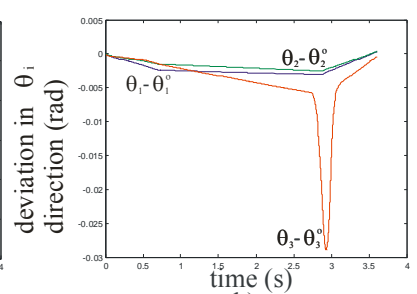

b)
Figure 10. a) Deviation real from the reference frame values of a motion trajectory of camera carrier, b) deviation real from the reference frame values of a motion trajectory of motor shaft, (Example 3)

This causes a significant deviation of the real position of third motor comparing to the reference frame, which reaches value:

$$
\left(\theta_{3}-\theta_{3}^{o}\right)_{\min }=-0.028[\mathrm{rad}],
$$

see Fig. 9b) and Fig. 10b).

This is all reflected in a bad position tracking of the camera carrier in the Cartesian coordinates:

$$
\begin{aligned}
& \left(z-z^{o}\right)_{\max }=+0.0048[\mathrm{~m}], \\
& \left(y-y^{o}\right)_{\max }=+0.0008[\mathrm{~m}],
\end{aligned}
$$

see Fig. 9a) and 10a). The main forces in Fig. 11a) are up to $54[\mathrm{~N}]$.

This analysis shows that the motion dynamics of individual motors depends significantly on the choice of $\mathrm{CPR}-\mathrm{C}$ construction type and its parameters. 


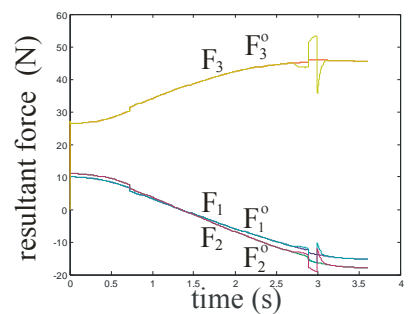

a)

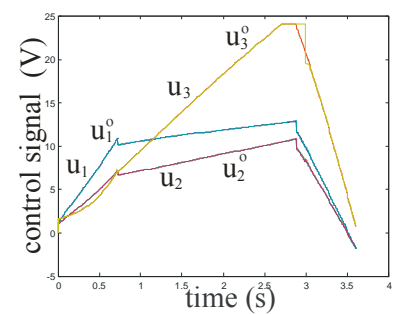

b)
Figure 11. a) Reference frame and real main forces $F_{i}$, b) reference frame and real control signal $u_{i}$, (Example 3 )
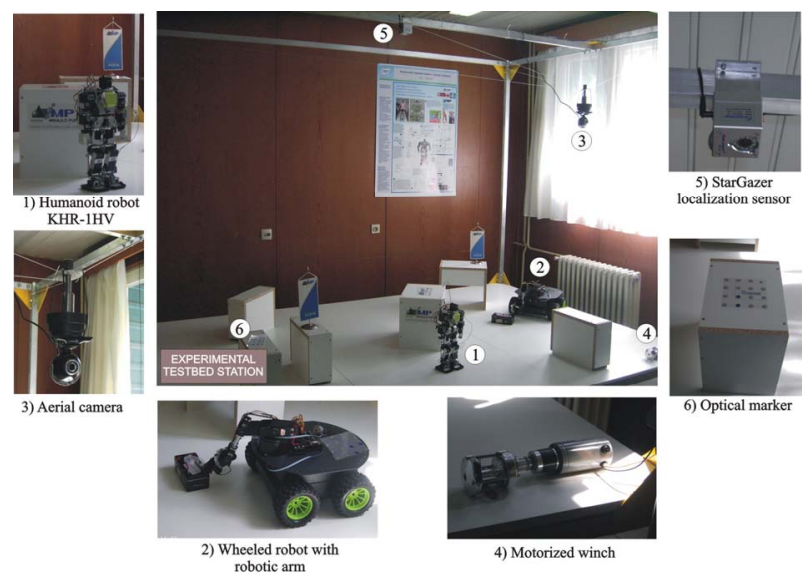

Figure 12. Organized work space with CPR system

This example confirms the property of the coupling between the motor motion and camera motion, as well.

The CPR-C system is modeled and analyzed by software package AIRCAMC.

The CPR device is developed in the Mihajlo Pupin Institute and is used to observe space. It is a part of more complex system presented in Fig. 12. The CPR system observes the area in which the humanoid robot and robotic vehicle.

\section{CONCLUSIONS}

The main contribution of this work can be defined in the following way.

The unique general type of the CPR-C mathematical model is defined. Kinematic model is generated for the system via Jacobian matrix. An adequate choice of generalized coordinates (in this paper, the internal coordinates), provides a mathematical model that illuminates the mapping of internal (main forces acting on the shaft of each motor) and external forces (acting on a camera carrier) by the Jacobian matrix on motion dynamics of each motor.

The presented CPR-C model is functionality generated by formulating and applying its highly authentic kinematic and dynamic model during synthesis and analysis which will enable further development and implementation of the current control laws. Software packages AIRCAMC is developed and used for individual and comparative analysis of the CPR-C system from various aspects. The influence of changing any parameters of the system (workspace dimensions, the mass of a camera carrier, change the size and dynamics of power disturbances, the choice of control law, the reference trajectory, and the presence of singularity avoidance system and a number of other characteristics) can be analyzed through this software package.

The selection of the motor components is extremely important for the CPR-C performance. The simulation results show the importance of the motor parameters selection, especially for the cases when some system properties are unknown. Motor type can significantly affect the response of the system or accuracy of the desired trajectory tracking.

The general mathematical model of the CPR-C system presented in this paper has been evaluated using several numerical examples. The model can be used for different applications, especially for following moving objects using integrated intelligence.

Future research intend at implementing the elastic ropes (type of nonlinear dynamic elasticity as defined in [11]-[18]) in the mathematical model of the CPR-C system. In this research several different models were developed and new models will be developed for different applications. All these models will be unified according to their similarities into one reconfigurable model, using the approached presented in [19] and [20].

\section{ACKNOWLEDGMENT}

This research has been supported by the Ministry of Education, Science and Technological Development, Government of the Republic of Serbia Grant TR-35003 through the following two projects: "Ambientally intelligent service robots of anthropomorphic characteristics," by Mihajlo Pupin Institute, University of Belgrade, Serbia, and partially supported by the project SNSF Care-robotics project no. IZ74Z0137361/1 by Ecole Polytechnique Federale de Lausanne, Switzerland.

We are grateful to Prof. Dr. Katica R. (Stevanovic) Hedrih from Mathematical Institute, Belgrade for helpful consultations during the implementation of this paper.

\section{REFERENCES}

[1] Gosselin C. and Angeles J.: The Optimum Kinematic Design of a Planar Three-Degree-ofFreedom Parallel Manipulator, Journal of Mechanisms, Transmissions, and Automation in Design, Vol. 110, pp. 35-41, March 1988.

[2] Fang J. and Huang Z.: Kinematics of a threedegree-of-freedom in-parallel actuated manipulator mechanism, Mech. Mach. Theory, Vol. 32, No 7, pp. 789-796, 1997.

[3] Borgstrom P.H., Borgstrom N.P., Stealey M. J., Jordan B., Sukhatme G., Batalin M. A. and Kaiser W. J.: Discrete Trajectory Control Algorithms for NIMS3D, an Autonomous Underconstrained ThreeDimensional Cabled Robot, Proceedings of the 2007 IEEE/RSJ International Conference on Intelligent Robots and Systems, Oct 29 - Nov 2. 2007, San Diego, CA, USA.

[4] Merlet J. P.: MARIONET, A Family of Modular Wire-Driven Parallel Robots, Advances in Robot Kinematics: Motion in Man and Machine, Part 1, pp. 53-61, 2010. 
[5] Gouttefarde M., Merlet J.-P. and Daney D.: Determination of the wrench-closure workspace of 6-DOF parallel cable-driven mechanisms, Advances in Robot Kinematics, Part 5, pp. 315-322, 2006.

[6] Bruckmann T., Mikelsons L., Schramm D., Hiller M.: Continuous workspace analysis for parallel cable-driven Stewart-Gough platforms, Special Issue: Sixth International Congress on Industrial Applied Mathematics (ICIAM07) and GAMM Annual Meeting, December 2007, Zürich, Volume 7 , Issue 1.

[7] Pott A.: Forward Kinematics and Workspace Determination of a Wire Robot for Industrial Applications, Advances in Robot Kinematics: Analysis and Design, Part 7, pp. 451-458, 2008.

[8] Miermeister P., Pott A. and Verl A.: AutoCalibration Method for Overconstrained CableDriven Parallel Robots, ROBOTIK 2012 - 7th German Conference on Robotics, 2012, Munich, Germany.

[9] Higuchi T., Ming A., and Jiang-Yu J.: Application of multi-dimensional wire crane in construction, In 5th Int. Symp. on Robotics in Construction, June 68. 1988, Tokyo, pp. 661-668.

[10] Duan B.Y.: A new design project of the line feed structure for large spherical radio telescope and its nonlinear dynamic analysis, Mechatronics, 9, pp. 53-64, 1998.

[11]Filipovic M.: Relation between Euler-Bernoulli Equation and Contemporary Knowledge in Robotics, Robotica, Cambridge University Press, Vol. 30, pp. 1-13, 2012.

[12] Filipović M. and Vukobratović M.: Complement of source equation of elastic line, Journal of Intelligent \& Robotic Systems, International Journal, Volume 52, No 2, pp. 233-261, June 2008.

[13] Filipović M. and Vukobratović M.: Expansion of source equation of elastic line," Robotica, Cambridge University Press, pp. 1-13, 2008.

[14] Hedrih (Stevanovic) K.: Dynamics of coupled systems, Nonlinear Analysis: Hybrid Systems, 2(2), pp. 310-334, 2008.

[15] Hedrih (Stevanovic) K.: Transversal vibrations of the axially moving sandwich belts," ARCH APPL MECH, 77(7), pp. 523-539, 2007.

[16] Raskovic D.: Theory of oscillations, Scientific book, Belgrade, Serbia, 1965.

[17] Rega G.: Nonlinear vibrations of suspended cablesPart I: modeling and analysis, ASME, APPL MECH REV, 57(6), pp. 443-478, 2004.

[18] Rega G.: Nonlinear vibrations of suspended cablesPart II: deterministic phenomena, ASME, APPL MECH REV, 57(6) 479-514, 2004.

[19]Djuric A., Saidi R. Al. and ElMaraghy W.: Dynamics Solution of n-DOF Global Machinery Model, Robotics and Computer Integrated Manufacturing (CIM)" Journal, Vol. 28, Issue 5, pp. 621-630, 2012.
[20] A. M. Djuric, R. Al Saidi and W. H. ElMaraghy, (2010), "Global Kinematic Model Generation for nDOF Reconfigurable Machinery Structure", 6th IEEE Conference on Automation Science and Engineering, CASE 2010, August 21-24. 2010, Toronto, Canada.

\section{NOMENCLATURE}

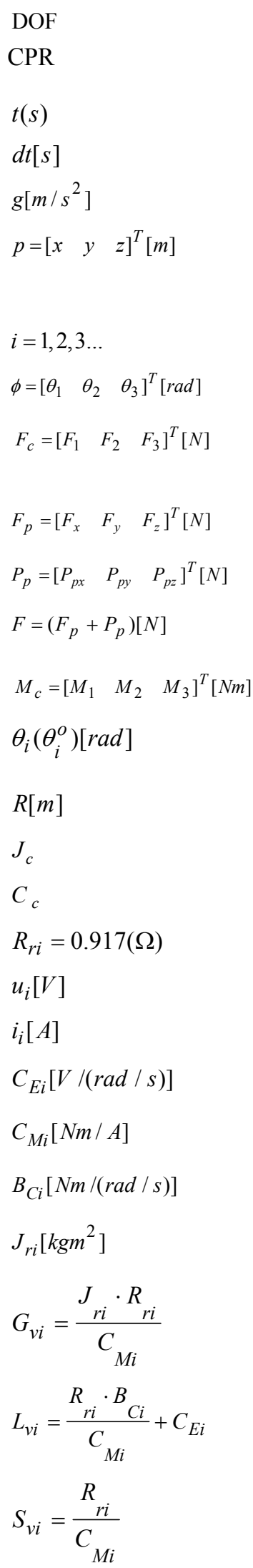

degree of freedom

Cable-suspended Parallel Robot

time

sample time

gravitational acceleration

position of camera carrier in space of Cartesian coordinates (external coordinate)

total number of DOF

vector of internal coordinates

vector main force acting on the shaft of each motor (motor force load)

force acting on the camera carrier

perturbation force acting on the camera carrier

whole forces acting on a camera carrier

motor moment load

rotation angle of the motor shaft after the reducer (desired value)

winch radius

Jacobian matrix

force mapping vector

rotor circuit resistance

voltage

rotor current

proportionality constant of electromotive force

proportionality constant of the moment friction

inertia moment of the rotor and reducer

characteristic of motor inertia

characteristic of motor damping

geometric characteristic of the motor coefficient of viscous 


\begin{tabular}{|c|c|}
\hline$m[\mathrm{~kg}]$ & mass of the camera carrier \\
\hline$d[m]$ & length of the recorded field \\
\hline$s[m]$ & width of the recorded field \\
\hline$v[m]$ & height of the recorded field \\
\hline$\delta \theta_{i}\left(t_{o}\right)(\mathrm{rad}), \delta \dot{\theta}_{i}\left(t_{o}\right)[\mathrm{rad} / \mathrm{s}]$ & $\begin{array}{l}\text { initial deviation of motor } \\
\text { rotating angle }\end{array}$ \\
\hline$K_{l p i}, K_{l v i}$ & $\begin{array}{l}\text { positional, velocity } \\
\text { amplification for motion } \\
\text { control }\end{array}$ \\
\hline$\diamond$ & $\begin{array}{l}\text { factor that characterizes two } \\
\text { parallel guided ropes }\end{array}$ \\
\hline
\end{tabular}

МАТЕМАТИЧКИ МОДЕЛ ВАЗДУШНЕ РОБОТИЗОВАНЕ КАМЕРЕ ЗАСНОВАН НА ГЕОМЕТРИЈСКИМ ВЕЗАМА

\author{
Мирјана Филиповић, Ана Ђурић
}

Овај рад приказује нови математички модел Ваздушне Роботизоване Камере (Цабле-суспендед Параллел Робот-ЦПР систем). Новина модела ЦПР система су геометријске везе измедју кретања камере у Картесијанским координатама (спољашњих координата) и угаоне позиције мотора у координатама зглоба (интерних координата). Повезаност је дефинисана преко Јакобијеве матрице, која се користи при решавању кинематике и динамике Ваздушне Роботизоване Камере. За израчунавање динамичког модела коришћен је Лагранжов принцип виртуелног рада. Јакобијева матрица, која је коришћена у формулацији Лагранжовог принципа виртуелног рада, је адаптирана према конструкцији механизма Ваздушне Роботизоване Камере. Особеност структуре Ваздушне Роботизоване Камере игра важну улогу при дефинисању кинематичког и динамичког модела ЦПР система. Дефинисана је и приказана генерална форма математичког модела ЦПР система. Неколико нумеричких примера је коришћено за потврду валидности ЦПР модела 